\title{
Agua, trasvases y medio ambiente. Los aspectos ambientales de los trasvases
}

\author{
Sebastián Félix Utrera-Caro*
}

* Doctor en Derecho de la Universidad de Alicante. Profesor agregado (titular) de Derecho Administrativo y Derecho Ambiental de la Universidad CEUSan Pablo, de Madrid, España.

Correo electrónico: utrcar@ceu.es

Recibido: 30 de noviembre del 2012 Aprobado: 3 de diciembre del 2012

Cómo citar este artículo:

Sebastián Félix Utrera-Caro. Agua, trasvases y medio ambiente. Los aspectos ambientales de los trasvases. DIXI. Junio 2013. At. 9.

\section{Resumen}

La Ley del Plan Hidrológico Nacional, la normativa de evaluación ambiental estratégica y la de evaluación de impacto ambiental, exigen realizar una previsión de los efectos en el entorno de los trasvases en todas sus fases de planificación, programación y proyectos.

Palabras clave: agua, evaluación ambiental estratégica, evaluación de impacto ambiental, medio ambiente, trasvase.

\section{Water, Transfers and the Environment. The EnVironmental Aspects of} Transfers

\section{Abstract}

The National Hydrological Plan Act and norms covering strategic environmental assessment and the environmental impact assessment require forecasting environmental effects during all phases of planning, programming and projects.

Keywords: water, strategic environmental assessment, environmental impact assessment, environment, transfer.

\section{ÁGUA, TRANSPOSIÇÕES E MEIO AMBIENTE. Os ASPECTOS AMBIENTAIS DAS TRANSPOSIÇÕES}

\section{Resumo}

A Lei do Plano Hidrológico Nacional, a normativa de avaliação ambiental estratégica e a de avaliação de impacto ambiental exigem realizar uma previsão dos efeitos no ambiente das transposições em todas suas fases de planificação, programação e projetos.

Palavras-chave: água, avaliação ambiental estratégica, avaliação de impacto ambiental, meio ambiente, transposição. 


\section{INTRODUCCIÓN ${ }^{1}$}

Los trasvases han sido una preocupación histórica en España, pero sólo hasta la década de los años setenta del siglo Xx no se materializaría el principal de los trasvases existentes hasta ahora: el Trasvase Tajo-Segura. ${ }^{2}$

Ya entonces se debatió sobre el Trasvase del Ebro, tema que se recogió en un conocidísimo libro encabezado por el maestro del derecho de aguas, Sebastián Martín-Retortillo Baquer, y titulado Aspectos jurídicos del Trasvase del Ebro, publicado en 1975 por la Caja de Ahorros de la Inmaculada, en Zaragoza. ${ }^{3}$

La evaluación de impacto ambiental nace con la Directiva 85/337/CE, dedicada sólo a la evaluación de proyectos de obra o actividad, y no es sino hasta la reforma de dicha ley - por la Directiva 97/11/CE - cuando se incluyen los trasvases entre el listado de proyectos obligatoriamente sometidos a evaluación de impacto ambiental.

En el 2000, España adapta su Real Decreto Legislativo 1302/1986 de evaluación de impacto ambiental a la Directiva 97/11/CE y recoge los trasvases en los Anexos I y II.

El Real Decreto Legislativo 1/2008, vigente en la actualidad, recoge el texto del Real Decreto Legislativo $1302 / 1986$ en este punto.

1 Esta publicación se enmarca en la investigación terminada denominada "La gestión del agua por cuencas fluviales y por Estados, regiones o comunidades autónomas: problemas y soluciones". Referencia: usp bs ppc013/2010. Agradezco a la Universidad ceu-San Pablo y al Banco Santander la ayuda prestada para llevar a cabo dicho proyecto.

2 Ver: Antonio Fanlo Loras. La Directiva Marco de Aguas: base jurídica medioambiental y principales contenidos. Revista Aranzadi de Derecho Ambiental. 2002, vol. 2. At. 57; Antonio Fanlo Loras. La unidad de gestión de las cuencas hidrográficas. Editorial Instituto Euromediterráneo del Agua. (2007); Antonio Fanlo Loras. La ordenación jurídica del Trasvase Tajo-Segura. Editorial Instituto Euromediterráneo del Agua. (2008); Antonio Fanlo Loras. El trasvase Tajo-Segura y su instrumentación jurídica. Editorial Civitas. (2008); Ramón Martín Mateo. Sobre trasvases, concesiones y convenios. El suministro de agua a la comarca del Vinalopó. Revista Española de Derecho Administrativo. 1997, № 96; Joaquín Melgarejo Moreno. El trasvase Tajo-Segura: repercusiones económicas, sociales y ambientales en la cuenca del Segura. Editorial Caja de Ahorros del Mediterráneo. (2009); Joaquín Melgarejo Moreno, Andrés Molina Giménez \& Alberto del Villar García. El valor socioeconómico del Trasvase TajoSegura: análisis jurídico y económico ante la hipótesis de su reducción o cancelación. Editorial Fundación Coepa para la formación. (2009).

$3 \mathrm{El}$ mismo autor ha escrito multitud de libros y artículos sobre derecho de aguas [ver Sebastián Martín Retortillo Baquer. Derecho de aguas. Editorial Civitas. (1997)] y fue el inspirador de la reforma de la Ley de Aguas de 1985 llevada a cabo por una ley de 1999. El 26 de octubre del 2012 se le rinde homenaje en la Universidad Complutense de Madrid exponiendo diversos trabajos sobre legislación de aguas en nuestro país.
La Directiva 2011/92/CE sustituye a la 85/337/CE en la regulación de la evaluación de impacto ambiental de proyectos y recoge los trasvases en sus Anexos I y II. Por tanto, su transposición también debe incluirlos.

\section{LEY 10/2001, DEL 5 DE JULIO, DEL Plan Hidrológico Nacional}

La "Exposición de motivos" de la Ley 10/2001, del 5 de julio, del Plan Hidrológico Nacional, señala que el artículo 45.2 de la Constitución Española establece que "los poderes públicos velarán por la utilización racional de todos los recursos naturales, con el fin de proteger y mejorar la calidad de la vida y defender y restaurar el medio ambiente, apoyándose en la indispensable solidaridad colectiva".

Añade que "Constituyendo el agua un recurso natural, su disponibilidad debe ser objeto de una adecuada planificación que posibilite su uso racional en armonía con el medio ambiente".

Y matiza que aunque la planificación es una técnica que goza de gran arraigo en nuestro ordenamiento jurídico, esta alcanza un significado nuevo con la Ley 29/1985, del 2 de agosto, de Aguas, que le da rango legal y concibe como instrumento de racionalización y de garantía de la disponibilidad del agua para satisfacer las diferentes demandas, pero también como objeto para alcanzar un buen estado ecológico de las aguas.

[...]

Y destaca que "esta planificación no puede entenderse en nuestros días sin que el medio ambiente sea la principal referencia de su contenido", ello debido a la Directiva Marco de Aguas del 2000. Por tanto, añade la "Exposición de motivos", que en este sentido, el presente Plan Hidrológico Nacional no puede permanecer indiferente a la reciente aprobación de la Directiva 2000/60/CE del Parlamento Europeo y del Consejo, del 23 de octubre, por la que se establece un marco comunitario de actuación en el ámbito de la política de aguas, patrón por el que deberán perfilarse las políticas hidráulicas de los Estados miembros en el siglo XxI.

También es debido a las recientes reformas de la Ley de Aguas:

Así, el Plan Hidrológico Nacional hace suyos los principios esenciales de la Directiva, prosiguiendo el camino ya iniciado por la reforma del artículo 38 de la Ley de Aguas, en virtud de la Ley 46/1999, de 13 de diciembre, 
al considerar como uno de sus objetivos "alcanzar el buen estado de las masas de agua”.

El principio de recuperación de costes, la participación de la sociedad en el proceso de elaboración del Plan Hidrológico Nacional, la garantía del acceso a la información en materia de aguas, son claros ejemplos de esta influencia y de la voluntad del legislador de incorporar a nuestro derecho de aguas la filosofía inspiradora de la Directiva.

Por ello, la redacción inicial del Capítulo III, "Previsión y condiciones de las transferencias", y concretamente su Sección I, "Principios generales y previsión de transferencias", ${ }^{4}$ establecía en su artículo 12, dedicado a los principios generales: ${ }^{5}$

1. Con el fin de dar cumplimiento a los objetivos generales recogidos en el artículo 38.1 de la Ley de Aguas y en el artículo 2 de esta Ley, podrán llevarse a cabo transferencias de recursos hídricos entre ámbitos territoriales de distintos Planes Hidrológicos de cuenca. Dichas transferencias estarán en todo caso supeditadas al cumplimiento de las condiciones que se prevén en la presente Ley.

2. Toda transferencia se basará en los principios de garantía de las demandas actuales y futuras de todos los usos y aprovechamientos de la cuenca cedente, incluidas las restricciones medioambientales, sin que pueda verse limitado el desarrollo de dicha cuenca amparándose en la previsión de transferencias. Se atenderá además a los principios de solidaridad, sostenibilidad, racionalidad económica y vertebración del territorio.

3. Las transferencias previstas en esta Ley deberán someterse igualmente al principio de recuperación de costes, de acuerdo con los principios de la Ley de Aguas y de la normativa comunitaria.

Y añadía en su artículo 13, "Previsión de nuevas transferencias ordinarias", que:

1. Se autorizan, con sujeción al cumplimiento de las condiciones recogidas en la presente Ley, las siguientes transferencias:

- La transferencia de un volumen anual de hasta $190 \mathrm{hm}^{3}$, con origen en la zona del Bajo Ebro del Plan Hidrológico de la cuenca del Ebro y

\footnotetext{
4 Ver Isabel Gallego Córceles. Régimen jurídico de los trasvases. Thom son Reuters - Civitas - Cortes. (2009)

5 Ver Antonio Fanlo Loras. La ordenación jurídica del Trasvase TajoSegura. Editorial Instituto Euromediterráneo del Agua. (2008).
}

destino en el ámbito territorial del Plan Hidrológico de las Cuencas Internas de Cataluña.

- La transferencia de un volumen anual de hasta $315 \mathrm{hm}^{3}$, con origen en la zona del Bajo Ebro del Plan Hidrológico de la cuenca del Ebro y destino en el ámbito territorial del Plan Hidrológico del Júcar.

- La transferencia de un volumen anual de hasta $450 \mathrm{hm}^{3}$, con origen en la zona del Bajo Ebro del Plan Hidrológico de la cuenca del Ebro y destino en el ámbito territorial del Plan Hidrológico del Segura. ${ }^{6}$

- La transferencia de un volumen anual de hasta $95 \mathrm{hm}^{3}$, con origen en la zona del Bajo Ebro del Plan Hidrológico de la cuenca del Ebro y destino en el ámbito territorial del Plan Hidrológico del Sur.

En cuanto a la redacción inicial del artículo 15, "Condiciones ambientales", señalaba que, con el fin de poder determinar las repercusiones ambientales de las transferencias, se someterán a evaluación de impacto ambiental de manera conjunta todos los proyectos relativos a dichas repercusiones, de acuerdo con el procedimiento legalmente establecido, incluso cuando ello no fuera preceptivo conforme a la legislación sobre evaluación de impacto ambiental, debiendo cumplir dichas transferencias las medidas preventivas, protectoras, correctoras y de compensación incluidas en las declaraciones de impacto ambiental que al efecto se dicten.

Posteriormente, la redacción del Real Decreto-Ley $2 / 2004$, dictado apresuradamente por el PsOE en cuanto llegó al poder, y de la Ley 11/2005, del 22 de junio, por la que se modifica la Ley 10/2001 del Plan Hidrológico Nacional es la siguiente: ${ }^{7}$

Capítulo III.Previsiónycondicionesdelastransferencias. Sección I. Principios generales y previsión de transferencias. El artículo 12 recoge los principios generales.

1. Con el fin de dar cumplimiento a los objetivos generales recogidos en el artículo 38.1 de la Ley de Aguas y en el artículo 2 de esta Ley, podrán llevarse a cabo transferencias de recursos hídricos entre

\footnotetext{
6 Ver Joaquín Melgarejo Moreno. El trasvase Tajo-Segura: repercusiones económicas, sociales y ambientales en la cuenca del Segura. Editorial Caja de Ahorros del Mediterráneo. (2009); Joaquín Melgarejo Moreno, Andrés Molina Giménez \& Alberto del Villar García. El valor socioeconómico del Trasvase Tajo-Segura: análisis jurídico y económico ante la hipótesis de su reducción o cancelación. Editorial Fundación Coepa para la formación. (2009).

7 Ver Ricardo Almenar \& Emerit Bono. Trasvase del Ebro y Comunidad Valenciana. Tirant lo Blanch. (2005).
} 
ámbitos territoriales de distintos planes hidrológicos de cuenca. Dichas transferencias estarán en todo caso supeditadas al cumplimiento de las condiciones que se prevén en la presente ley.

2. Toda transferencia se basará en los principios de garantía de las demandas actuales y futuras de todos los usos y aprovechamientos de la cuenca cedente, incluidas las restricciones medioambientales, sin que pueda verse limitado el desarrollo de dicha cuenca amparándose en la previsión de transferencias. Se atenderá además a los principios de solidaridad, sostenibilidad, racionalidad económica y vertebración del territorio.

3. Las transferencias previstas en esta ley deberán someterse igualmente al principio de recuperación de costes, de acuerdo con los principios de la Ley de Aguas y de la normativa comunitaria.

El artículo 13 ha sido derogado totalmente.

En cuanto al artículo 15, dedicado a las condiciones ambientales, actualmente señala que

[...] con el fin de poder determinar las repercusiones ambientales de las transferencias, se someterán a evaluación de impacto ambiental todos los proyectos de manera individual y conjunta y, en su caso, planes y programas relativos a las mismas, tanto los afectantes a las cuencas cedentes como a las receptoras, de conformidad con el procedimiento establecido por la normativa que resulte de aplicación. En los supuestos en que la normativa de aplicación no haya previsto la evaluación de impacto ambiental para las transferencias, todos los proyectos relativos a las mismas se someterán a la evaluación de impacto ambiental de manera conjunta, debiendo cumplir dichas transferencias las medidas preventivas, protectoras, correctoras y de compensación incluidas en las declaraciones de impacto ambiental que al efecto se dicten".

8 Así se reitera y refuerza la prohibición de fraccionar el proyecto a efectos de eludir la evaluación de impacto ambiental. [Ver Antonio Ezquerra Huerva. El régimen jurídico de las obras hidráulicas. Instituto Euromediterráneo del Agua. (2007)]. Tomás Quintana López ha señalado que la nueva redacción del artículo 15 de la Ley del PHN supone una generalización de la evaluación de impacto ambiental de todos los proyectos que exijan la ejecución de las infraestructuras relativas a nuevas transferencias de recursos hídricos de un ámbito territorial de la planificación hidrológica a otro distinto. Todos los proyectos necesarios para la realización de las transferencias de aguas entre cuencas deberían someterse a la evaluación de impacto ambiental. [Ver Tomás Quintana López. La evaluación ambiental de los trasvases y sus actuaciones. La ordenación jurídica del Trasvase Tajo-Segura. Pág. 337. Fundación Instituto Euromediterráneo del Agua. (2008)].
Conviene destacar en el actual artículo 12 el respeto a las restricciones medioambientales.

En el artículo 15 se encuentra la evaluación ambiental de planes y programas que se conoce como evaluación ambiental estratégica, y la evaluación de impacto ambiental de cada transferencia o evaluación de impacto ambiental de proyectos. A continuación analizaremos cada una de ellas. ${ }^{9}$

Pero antes recordaremos que la disposición adicional tercera, párrafo 3, de la Ley 11/2005, del 22 de junio, establece que el Ministerio de Medio Ambiente, en coordinación con las Comunidades Autónomas afectadas, tendrá en cuenta las implicaciones para la gestión del Trasvase Tajo-Segura derivadas de las exigencias contenidas en la Directiva Marco del Agua, exigencias entre las que se encuentran los objetivos medioambientales previstos por el artículo 4 de la Directiva 2000/60/ CE, de 23 de octubre, conocida como Directiva Marco del Agua, a los cuales, por cierto, por imposición del artículo 13 se tienen que referir los planes hidrológicos de cuenca, ${ }^{10}$ en la actualidad aprobados mediante Real Decreto 1664/1998, de 24 de julio, y publicadas sus determinaciones normativas por Orden del Ministerio de Medio Ambiente de 13 de agosto de 1999, por la que se establece la publicación de los planes hidrológicos de cuenca.

Los planes hidrológicos de cuenca están siendo modificados y aprobados por el Gobierno como planes hidrológicos de demarcaciones hidrográficas. El 14 de septiembre del 2012 se aprobaron varios de ellos. ${ }^{11} \mathrm{El}$

9 Ver Juan Cruz Alli Aranguren. El Plan Hidrológico Nacional y la evaluación ambiental estratégica. El Derecho de aguas en Iberoamérica y España: cambio y modernización en el inicio del tercer milenio, 2002 vol. I. At. 355; Isabel Gallego Córcoles. Régimen jurídico de los trasvases. Thomson-Reuters - Civitas - Cortes. (2009); Antonio Fanlo Loras. La ordenación jurídica del Trasvase Tajo-Segura. Instituto Euromediterráneo del Agua. (2008); Antonio Fanlo Loras. El trasvase Tajo-Segura y su instrumentación jurídica. Editorial Civitas. (2008); Tomás Quintana López. La evaluación ambiental de los trasvases y sus actuaciones. La ordenación jurídica del Trasvase Tajo-Segura. Fundación Instituto Euromediterráneo del Agua. (2008).

10 Ver Anna Pallarés Serrano. La planificación hidrológica de cuenca como instrumento de ordenación ambiental sobre el territorio. Tirant lo Blanch. (2007).

11 El Consejo de Ministros aprobó en septiembre del 2012 -a propuesta del Ministerio de Agricultura, Alimentación y Medio Ambiente (Magrama) - los Reales Decretos de los planes hidrológicos de las demarcaciones de Galicia-Costa, Tinto-Odiel-Piedras, Guadalete-Barbate y de las Cuencas Mediterráneas Andaluzas. Se avanza así en el proceso de planificación hidrológica en las cuencas hidrográficas españolas, impulsando la coordinación de todos los intereses territoriales y garantizando el cumplimiento de la Directiva Marco del Agua y de los preceptos del texto refundido de la Ley de Aguas que la traspone en España. Estos cuatro planes han sido elaborados por la administración hidráulica competente 
proceso está siendo muy lento, y en octubre del 2012 el Tribunal de Justicia de la Unión Europea llamó la atención a España por el retraso en aprobar estos planes. La Sentencia del Tribunal de Justicia de la Unión Europea del 4 de octubre del 2012 falla que:

1) Al no haber adoptado, a 22 de diciembre del 2009 , los planes hidrológicos de cuenca, salvo en el caso del Distrito de la Cuenca Fluvial de Cataluña,

- $\quad$ a al no haber enviado a la Comisión Europea y a los demás Estados miembros interesados, a 22 de marzo del 2010, un ejemplar de dichos planes, conforme a los artículos 13, apartados 1 a 3 y 6 , y 15, apartado 1, de la Directiva 2000/60/CE del Parlamento Europeo y del Consejo, de 23 de octubre del 2000, por la que se establece un marco comunitario de actuación en el ámbito de la política de aguas, en su versión modificada por la Directiva 2008/32/ CE del Parlamento Europeo y del Consejo, de 11 de marzo del 2008, y

(la autonómica, al tratarse de cuencas hidrográficas comprendidas en el ámbito territorial de una comunidad), de acuerdo con el Reglamento de Planificación Hidrológica, y examinados por la Dirección General del Agua del Ministerio de Agricultura, Alimentación y Medio Ambiente. Posteriormente, el pasado 28 de junio, estos cuatro planes de cuenca fueron aprobados por el Consejo Nacional del Agua, a propuesta del Ministerio y tras someterse a un trámite de información pública durante al menos seis meses. En dicho Consejo Nacional del Agua también se aprobó el plan de la cuenca del Miño-Sil, que se elevará próximamente al Consejo de Ministros. El Consejo Nacional del Agua es el órgano asesor del Gobierno en esta materia en el que están representados la Administración General del Estado, las Comunidades Autónomas, los entes locales, los organismos de cuenca, las organizaciones profesionales y económicas relacionadas con los distintos usos del agua, las organizaciones sindicales y empresariales y las entidades sin ánimo de lucro estatales. El objetivo del Gobierno es aprobar los planes de cuenca de las demarcaciones competencia del Estado (intercomunitarias) en 2013 -inicialmente debían estar aprobados en 2009-, e impulsar que en ese plazo se apruebe el mayor número de los planes de las cuencas intracomunitarias (de competencia autonómica), de acuerdo con la Directiva Marco del Agua, evitando así posibles sanciones comunitarias. El presidente de la Confederación Hidrográfica del Guadalquivir (CHG), Manuel Romero Ortiz, ha dicho que el proyecto de Plan Hidrológico de la cuenca aprobado hoy rebaja la inversión desde los 4.106 millones inicialmente previstos a 1.738 "por realismo" y "para adaptarse a la nueva situación económica”. El documento, aprobado por el Consejo del Agua de la demarcación, acota esta menor inversión al año 2015, mientras que los 4.106 millones de euros inicialmente previstos en el anterior borrador, aprobado poco antes del cambio de gobierno central y andaluz, se habían programado hasta el 2027. El nuevo Plan Hidrológico del Guadalquivir ha sido aprobado por 55 de los 71 miembros asistentes al Consejo del Agua, representantes del Gobierno central y de los de Extremadura, Castilla-La Mancha y Murcia, así como por los regantes de la cuenca. Los catorce representantes de la Junta de Andalucía se han abstenido y los dos delegados de organizaciones ecologistas han votado en contra, ha señalado Romero. En su opinión, la nueva previsión de inversiones es "realista" porque se adapta "a la nueva situación económica del país"
- al no haber iniciado, a más tardar el 22 de diciembre de 2008, salvo en el caso de los planes hidrológicos de Distrito de la Cuenca Fluvial de Cataluña, Islas Baleares, Tenerife, Guadiana, Guadalquivir, Cuenca Mediterránea Andaluza, Tinto-Odiel-Piedras, Guadalete-Barbate, Galicia-Costa, Miño-Sil, Duero, Cantábrico Occidental y Cantábrico Oriental, el procedimiento de información y consulta públicas sobre los proyectos de los planes hidrológicos de cuenca, conforme al artículo 14, apartado 1, letra c), de la citada Directiva,

ha incumplido las obligaciones que le incumben en virtud de dichas disposiciones.

2) Condenar en costas al Reino de España.

\section{LA EVALUACIÓN AMBIENTAL ESTRATÉGICA DE PLANES Y PROGRAMAS RELATIVOS A LAS TRANSFERENCIAS DE AGUAS}

En la toma de decisiones públicas suelen seguirse cuatro fases: las políticas, los planes, los programas y los proyectos, así: las políticas (p. ej. la política de aguas) son desarrolladas por planes (p. ej. el Plan Hidrológico Nacional o los planes hidrológicos de cuencas hidrográficas aprobados por el Real Decreto en 1998); los

y sólo incluye "las obras ya en marcha o a punto de adjudicarse porque vamos a intentar cumplirlas todas". Este documento - que deberá ratificar el Consejo Nacional del Agua y el Consejo de Ministros- sustituye el Plan Hidrológico vigente desde 1998, ha sido debatido durante los últimos cinco años por numerosos colectivos en 18 jornadas participativas y ha sido sometido a centenares de alegaciones presentadas en los tres periodos de información pública a los que ha sido sometido. Esta nueva planificación del Guadalquivir, que adquirirá rango de ley cuando la apruebe el Consejo de Ministros, obligará a reducir la actual demanda de 4.004 hectómetros cúbicos anuales en 228,6 , hasta los 3.775,48 hectómetros cúbicos previstos para el 2015, una reducción menos exigente que los 3.597 hectómetros cúbicos previstos en el anterior Plan. Este ahorro se logrará, fundamentalmente, mediante la reducción de pérdidas por la mejora de las conducciones para regadío y abastecimiento urbano y por una mayor eficiencia de los cultivos. De hecho, el Plan acepta alegaciones de agricultores para aumentar su dotación de riego siempre que esta agua se obtenga del ahorro logrado por la modernización de sus regadíos. Romero Ortiz ha recordado que las 850.000 hectáreas de regadío de la cuenca consumen unos 3.500 hectómetros cúbicos al año, el 87 por ciento de toda la demanda, mientras que el abastecimiento a los 4,1 millones de personas de la demarcación absorbe 436 hectómetros cúbicos, el once por ciento de la demanda. Junto con la garantía de cobertura de esta demanda, el nuevo Plan Hidrológico asume las directrices de la Directiva Marco del Agua de la UE para incorporar criterios ecológicos en la planificación y gestión hidrográficas del Guadalquivir. 
planes son desarrollados mediante programas (p. ej. programa de depuración de aguas, o programa AGUA de actuaciones de gestión y uso del agua que comprende multitud de desaladoras como alternativa socialista a los trasvases) y estos a su vez son desarrollados por proyectos concretos de obras (p. ej. desaladora de Águilas en Murcia, depuradora de La Gavia en Madrid).

La evaluación ambiental estratégica nace en Estados Unidos con la National Environmental Policy Act, de 1969 - que entró en vigor el 1 de enero de 1970— la cual se refiere a los planes y programas, a diferencia de la evaluación de impacto ambiental ordinaria, que se refiere a los proyectos concretos. ${ }^{12}$

Las diferencias entre una y otras han sido sistematizadas por la doctrina: ${ }^{13}$ son de ámbito temporal y material de aplicación, contenido y metodologías de realización. Más concretamente, serían que en la evaluación ambiental estratégica el momento temporal de realización se adelanta a las etapas iniciales de toma de decisión, su enfoque conceptual es más que geográfico o técnico, tiene una orientación adaptativa más que reactiva o semiadaptativa, ampliación del elenco de potenciales alternativas, consideración temprana de los efectos acumulativos, visión amplia de los objetivos ambientales y menor nivel de detalle y concreción técnica.

La Ley 9/2006, del 28 de abril, sobre evaluación de los efectos de determinados planes y programas en el medio ambiente - que transpone la Directiva 2001/42 sobre la misma materia - prevé en su artículo 2: a) una definición de planes y programas: el conjunto de estrategias, directrices y propuestas que prevé una administración pública para satisfacer necesidades sociales no ejecutables directamente sino a través de su desarrollo

12 Ver Juan Rosa Moreno. Régimen jurídico de la evaluación de impacto ambiental. Trivium. (1993); Juan Rosa Moreno. La evaluación ambiental estratégica en la planificación de infraestructuras. III Congreso Nacional de Derecho Ambiental. (2000); Sebastián Félix Utrera Caro. La incidencia ambiental de las obras hidráulicas. Régimen jurídico. Dykinson. (2002); Sebastián Félix Utrera Caro. La evaluación de impacto ambiental de las obras hidráulicas. Comentario a la legislación de evaluación de impacto ambiental. 2002. At. 209; Sebastián Félix Utrera Caro. La evaluación ambiental de las obras hidráulicas. Derecho de aguas. Instituto Euromediterráneo del Agua. 2006. At. 909.

13 Ver Nuria Garrido Cuenca. La evaluación ambiental estratégica de políticas, planes y programas. Revista Aranzadi de Derecho Ambiental. 2004, No 5; Nuria Garrido Cuenca. Intervención pública y sostenibilidad medioambiental: análisis desde el punto de vista de la organización administrativa y la integración de los principios de coordinación, cooperación y participación. Situación actual, balance y perspectivas. Revista Aranzadi de Derecho Ambiental. 2008, No 13. At. 272; Isabel Gallego Córcoles. Régimen jurídico de los trasvases. Pág. 256. Thomson-Reuters - Civitas - Cortes. (2009); Juan Rosa Moreno. La evaluación ambiental estratégica en la planificación de infraestructuras. III Congreso Nacional de Derecho Ambiental. (2000). por medio de un conjunto de proyectos de cuya dicción es destacable la idea de pluralidad de proyectos vinculados por una estrategia o directriz común.

Asimismo, en su artículo 3, "Ámbito de aplicación", numeral 1, incluye que serán objeto de evaluación ambiental los planes y programas - y sus modificaciones- que puedan tener efectos significativos sobre el medio ambiente y que cumplan los dos siguientes requisitos: a) que se elaboren o aprueben por una administración pública, b) que su elaboración y aprobación venga exigida por una disposición legal o reglamentaria o por acuerdo del Consejo de Ministros o del Consejo de Gobierno de una comunidad autónoma.

En el numeral 2 del mismo artículo indica que se entenderá que tienen efectos significativos sobre el medio ambiente aquellos planes y programas que tengan cabida en alguna de las siguientes categorías:

a. Los que establezcan el marco para la futura autorización de proyectos legalmente sometidos a evaluación de impacto ambiental en las siguientes materias: agricultura, ganadería, silvicultura, acuicultura, pesca, energía, minería, industria, transporte, gestión de residuos, gestión de recursos hídricos, ocupación del dominio público marítimo terrestre, telecomunicaciones, turismo, ordenación del territorio urbano ${ }^{14} \mathrm{y}$ rural, o del uso del suelo. ${ }^{15}$ b. Los que requieran una evaluación conforme a la normativa reguladora de la Red Ecológica Europea

14 Ver Tribunal Supremo. Sección 5a Sala de lo Contencioso-Administrativo. (Ponente: Jesús Ernesto Peces Morate / 2012). Esta Sentencia resulta de interés para determinar el ámbito de aplicación de la evaluación ambiental estratégica y, más concretamente, cuándo un plan tiene o no "efectos significativos sobre el medio ambiente". Concretamente, el Tribunal Supremo interpreta que en supuestos de modificación de un Plan General de Ordenación Urbana, aun cuando esta modificación no tenga que someterse necesariamente a evaluación ambiental por imperativo del artículo 3.2 de la Ley 9/2006 - al no establecer un marco para la futura autorización de proyectos legalmente sometidos a evaluación de impacto ambiental - tampoco puede excluirse de antemano la evaluación ambiental. En estos casos la modificación deberá someterse a dicha evaluación, en los términos previstos en el artículo 4 de la misma Ley, por preverse que pueda tener efectos significativos en el medio ambiente. De este modo, la determinación de la existencia o no de efectos significativos en el medio ambiente que pueda acarrear la modificación puntual de un Plan General de Ordenación Urbana incumbe al órgano ambiental, que habrá de consultar previamente a las administraciones públicas afectadas.

Por otra parte, el Tribunal Supremo también destaca en esta Sentencia la independencia entre evaluación ambiental de planes y programas y evaluación de impacto ambiental de proyectos. La primera no excluye la aplicación de la segunda, es independiente de ella. Por ello, puede resultar exigible la evaluación ambiental de un plan o programa y de sus modificaciones aunque las instalaciones o actividades que dicho plan o programa autoricen no se sujeten a evaluación de impacto ambiental.

15 Ver Tribunal de Justicia. Sala Cuarta. (22 de marzo del 2012). 
Natura 2000, regulada en la Ley 4/1989, de 27 de marzo, de conservación de los espacios naturales y de la flora y la fauna silvestres. ${ }^{16}$

Quintana López ${ }^{17}$ señala que, en virtud de la Ley 9/2006, es posible afirmar que el conjunto de proyectos de infraestructuras cuya ejecución sea necesaria para efectuar el trasvase de recursos hídricos entre cuencas fluviales, se halla sometido, como unidad que es, a la evaluación estratégica, pues en cuanto instrumento unitario no cabe duda de que constituye el marco para la futura autorización de proyectos legalmente sometidos a evaluación de impacto ambiental, como nos consta que lo están los proyectos relativos a las transferencias de recursos hídricos con la extensión que hemos deducido del artículo 15 de la Ley 10/2001, en la redacción dada a dicho artículo por la Ley 11/2005, de 22 de junio.

En la evaluación ambiental estratégica se incluyen los acuerdos relativos a las transferencias a realizar en cada ejercicio, debido a los efectos acumulados que pueden tener las distintas transferencias que se proyecten. ${ }^{18}$ No se someterían a evaluación ambiental estratégica las autorizaciones concretas de derivar caudales, ya que estas no pueden ser conceptuadas de ningún modo como planes o programas.

\section{LA EVALUACIÓN DE IMPACTO AMBIENTAL DE PROYECTOS ${ }^{19}$}

\section{A. La Directiva $85 / 337 / C E E$}

\section{Redacción inicial}

La Directiva en su versión inicial no recogía los trasvases en sus listas de proyectos obligados a evaluación.

16 Actualmente Ley de 2007 de Patrimonio Natural y Biodiversidad. La Red Europea Natura 2000 recoge todos los espacios naturales protegidos de la Unión Europea; en España comprende el 25\% del territorio, correspondiente a todo tipo de espacios naturales: parques nacionales, parques naturales, reservas naturales.

17 Ver Quintana, supra cita 9, At. 344-346.

18 Id. At. 346.

19 Ver Sebastián Félix Utrera Caro. La incidencia ambiental de las obras hidráulicas. Régimen jurídico. Dykinson. 2002; Sebastián Félix Utrera Caro. La evaluación de impacto ambiental de las obras hidráulicas. Comentario a la legislación de evaluación de impacto ambiental. 2002. At. 209-253; Sebastián Félix Utrera Caro. La evaluación ambiental de las obras hidráulicas. Derecho de aguas. Instituto Euromediterráneo del Agua. 2006. At. 909-927.

\section{Redacción de 1997}

En su modificación operada por la Directiva 97/11 del 3 de marzo, sí se recogen por primera vez las obras para el trasvase de recursos hídricos entre cuencas fluviales como actuaciones sometidas o susceptibles de estarlo a evaluación ambiental. ${ }^{20}$

\section{B. La Directiva $2011 / 92 / c e$, del 13 de diciembre ${ }^{21}$}

En su anexo I, grupo 12, letras a) y b), la Directiva 2011/92CE recoge los trasvases así:

12. a) Obras para el trasvase de recursos hídricos entre cuencas fluviales cuando dicho trasvase tenga por objeto evitar la posible escasez de agua y cuando el volumen de agua trasvasada sea superior a 100 millones de metros cúbicos al año.

b) En todos los demás casos, proyectos de trasvase de recursos hídricos entre cuencas fluviales cuando el flujo medio plurianual de la cuenca de la extracción supere los 2.000 millones de metros cúbicos al año y cuando el volumen de agua trasvasada supere el $5 \%$ de dicho flujo.

En esta definición entrarían muchos de los actuales y futuros trasvases, pues las cantidades umbral no son muy elevadas.

Igualmente el resto de trasvases están incluidos en su anexo II, grupo 10, letra m), en la que se lee: “Obras

20 La evaluación de impacto ambiental de proyectos es una materia que ha producido una elevadísima cantidad de sentencias del Tribunal de Justicia de la Unión Europea. Véanse las recientes sstjue (Gran Sala) del 18 de octubre del 2011 sobre actos legislativos nacionales específicos, acceso a la tutela judicial y a los recursos, y la sTjue (Sala Cuarta) del 16 de febrero del 2012 sobre evaluación de impacto ambiental de proyectos, concretamente sobre la exclusión de dicha evaluación mediante acto legislativo concreto y por razón imperiosa de interés público.

21 Ver Juan Cruz Alli Aranguren. La Directiva 2011/92/UE, codificación del régimen de la evaluación de impacto ambiental de proyectos. Una ocasión perdida para mejorar el sistema. Revista de Derecho Urbanístico y Medio Ambiente. 2012, No. 275. At. 127-176; Teresa Parejo Navajas. Comentario sobre la Directiva 2011/92/UE del Parlamento Europeo y del Consejo, de 13 de diciembre del 2011, relativa a la evaluación de las repercusiones de determinados proyectos públicos y privados sobre el medio ambiente. Revista General de Derecho Europeo. 2012. No. 27. En dicho artículo la autora nos recuerda que la Directiva 2011/92/UE viene a refundir la regulación relativa a la evaluación de las repercusiones de determinados proyectos públicos y privados sobre medio ambiente hasta ahora dispersa en tres textos normativos: Directiva 85/337/CEE; Directiva 97/11/CE del Consejo; artículo 3 de la Directiva 2003/35/CE y artículo 31 de la Directiva 2009/31/CE, referidos ambos a la modificación de la Directiva 85/337/CE-, sin introducir por ello importantes cambios en la regulación de la materia, pero contribuyendo a su mayor claridad. 
de trasvase de recursos hídricos entre cuencas fluviales (no incluidas en el anexo I)".

Estas obras del Anexo II se evalúan o no dependiendo de la aplicación al proyecto de los criterios del Anexo III, entre los que figuran su magnitud y la importancia del impacto.

\section{El Real Decreto Legislativo 1302/1986,} de 26 de junio, por el que se aprueba el Texto Refundido de la Ley de Evaluación de Impacto Ambiental de Proyectos

\section{Redacción inicial}

No recoge los trasvases, pues no lo hacía la Directiva 85/337/CEE en su redacción originaria.

\section{Redacción del 2000}

Mediante el Real Decreto-Ley 9/2000, en octubre de dicho año se transpone la Directiva 97/11/CE y se añaden por primera vez los trasvases a los proyectos sometidos a evaluación de impacto ambiental en España. ${ }^{22}$

Así, el artículo 1.2 en relación con la letra c) del grupo 7 del anexo I, señala que deberán someterse a evaluación de impacto ambiental, en la forma prevista en el propio Real Decreto Legislativo, los proyectos para el trasvase de recursos hídricos entre cuencas fluviales, excluidos los trasvases de agua potable por tubería, en cualquiera de los siguientes supuestos:

1. Que el trasvase tenga por objeto evitar la posible escasez de agua y el volumen de agua trasvasada sea superior a 100.000.000 de metros cúbicos al año.

2. Que el flujo medio plurianual de la cuenca de la extracción supere los 2.000.000.000 de metros cúbicos al año y el volumen de agua trasvasada supere el 5 por ciento de dicho flujo.

3. En todos los demás casos, cuando alguna de la obras que constituyen el trasvase figure entre las comprendidas en este Anexo I del mismo Real Decreto Legislativo.

22 Ver José Antonio Razquín Lizárraga. La evaluación de impacto ambiental. Aranzadi. (2000); Sebastián Félix Utrera Caro. La incidencia ambiental de las obras hidráulicas. Régimen jurídico. Dykinson. (2002); Sebastián Félix Utrera Caro. La evaluación de impacto ambiental de las obras hidráulicas. Comentario a la legislación de evaluación de impacto ambiental. Civitas. 2002. At. 209-253; Sebastián Félix Utrera Caro. La evaluación ambiental de las obras hidráulicas. Derecho de aguas. Instituto Euromediterráneo del Agua. 2006. At. 909-927; Lorenzo Mellado Ruiz. Gestión sostenible del agua y evaluación de impacto ambiental de obras hidráulicas. Comares. (2004).
Y en relación con el Anexo II, grupo 8, letra b), el artículo 1.3 señala que los proyectos de trasvase de recursos hídricos entre cuencas fluviales cuando el volumen de agua trasvasada sea superior a 5.000.000 de metros cúbicos, excepto los trasvases de agua potable por tubería o la reutilización directa de aguas depuradas, sólo se deberán someter a evaluación de impacto ambiental cuando así lo decida el órgano ambiental en cada caso, aplicando para ello los criterios que establece el Anexo III del mismo texto legal, a no ser que la evaluación de impacto ambiental, con este límite $\mathrm{u}$ otro inferior se entiende, venga impuesta por la normativa de las Comunidades Autónomas en el ámbito de sus competencias, bien directamente o bien a través de la disposición de umbrales fijados conforme a los criterios previstos en el Anexo III del citado Real Decreto Legislativo. ${ }^{23}$

D. El Real Decreto Legislativo 1/2008, de 11 de enero, por el que se aprueba el texto refundido de la Ley de Evaluación de Impacto Ambiental de proyectos

\section{1. Ámbito de aplicación: los trasvases}

En su artículo 3, dedicado al ámbito de aplicación, establece que los proyectos - públicos y privadosconsistentes en la realización de obras, instalaciones o cualquier otra actividad comprendida en el Anexo I, deberán someterse a una evaluación de impacto ambiental en la forma prevista en esta Ley.

$\mathrm{Y}$ añade que sólo deberán someterse a una evaluación de impacto ambiental en la forma prevista en esta Ley, cuando así lo decida el órgano ambiental en cada caso, los siguientes proyectos:

a. Los proyectos públicos o privados consistentes en la realización de las obras, instalaciones o de cualquier otra actividad comprendida en el Anexo II.

b. Los proyectos públicos o privados no incluidos en el Anexo I que puedan afectar directa o indirectamente los espacios de la Red Natura 2000.

La decisión, que debe ser motivada y pública, se ajustará a los criterios establecidos en el Anexo III.

La normativa de las comunidades autónomas podrá establecer - bien mediante el análisis caso a caso,

\footnotetext{
23 Ver Jorge Agudo González. Ejecución y gestión de obras hidráulicas. Nuevos retos, nuevos conflictos, Comares. (2008); Jorge Agudo González. El Derecho de aguas en clave europea, La Ley. (2010).
} 
bien mediante la fijación de umbrales y de acuerdo con los criterios del Anexo III- que los proyectos a los que se refiere este apartado se sometan a evaluación de impacto ambiental.

Finalmente dedica el Anexo I a los proyectos contemplados en el apartado 1 del artículo 3, y dentro de ellos el Grupo 7. Proyectos de ingeniería hidráulica y de gestión del agua; señala que serán objeto de evaluación:

a. Presas y otras instalaciones destinadas a retener el agua o almacenarla permanentemente cuando el volumen nuevo o adicional de agua almacenada sea superior a 10.000.000 de metros cúbicos.

b. Proyectos para la extracción de aguas subterráneas o la recarga artificial de acuíferos, si el volumen anual de agua extraída o aportada es igual o superior a 10.000.000 de metros cúbicos.

c. Proyectos para el trasvase de recursos hídricos entre cuencas fluviales, excluidos los trasvases de agua potable por tubería, en cualquiera de los siguientes casos:

1. Que el trasvase tenga por objeto evitar la posible escasez de agua y el volumen de agua trasvasada sea superior a 100.000 .000 de metros cúbicos al año.

2. Que el flujo medio plurianual de la cuenca de la extracción supere los 2.000.000.000 de metros cúbicos al año y el volumen de agua trasvasada supere el $5 \%$ de dicho flujo.

3. En todos los demás casos, cuando alguna de las obras que constituye el trasvase figure entre las comprendidas en este Anexo I.

Y añade en su Anexo II, dedicado a los proyectos contemplados en el apartado 2 del artículo 3, que existen los proyectos del Grupo 8. Proyectos de ingeniería hidráulica y de gestión del agua que incluyen:

a. Extracción de aguas subterráneas o recarga de acuíferos cuando el volumen anual de agua extraída o aportada sea superior a 1.000.000 de metros cúbicos (proyectos no incluidos en el Anexo I).

b. Proyectos para el trasvase de recursos hídricos entre cuencas fluviales cuando el volumen de agua trasvasada sea superior a 5.000.000 de metros cúbicos. ${ }^{24}$ Se exceptúan los trasvases de agua potable por tubería o la reutilización directa de aguas depuradas (proyectos no incluidos en el Anexo I).

24 Por tanto parecen excluirse los trasvases de caudal inferior a 5.000.000 de metros cúbicos. f. Instalaciones de conducción de agua a larga distancia cuando la longitud sea mayor de 40 kilómetros y la capacidad máxima de conducción sea superior a 5 metros cúbicos/segundo (proyectos no incluidos en el Anexo I).

g. Presas y otras instalaciones destinadas a retener el agua o almacenarla, siempre que se dé alguno de los siguientes supuestos:

1. Grandes presas según se definen en el Reglamento técnico sobre seguridad de presas y embalses, aprobado por Orden de 12 de marzo de 1996, cuando no se encuentren incluidas en el Anexo I.

2. Otras instalaciones destinadas a retener el agua, no incluidas en el apartado anterior, con capacidad de almacenamiento, nuevo o adicional, superior a 200.000 metros cúbicos.

2. Órganos competentes para la evaluación de impacto ambiental y para la autorización de los trasvases ${ }^{25}$

El Real Decreto Legislativo 1/2008 matiza en su artículo 4, "Competencias", que a efectos de lo establecido en esta Ley y, en su caso, en la legislación de las comunidades autónomas, el Ministerio de Medio Ambiente será órgano ambiental en relación con los proyectos que deban ser autorizados o aprobados por la Administración General del Estado. ${ }^{26}$

Igualmente señala que cuando se trate de proyectos distintos a los señalados en el apartado 1, será órgano ambiental el que determine cada comunidad autónoma en su respectivo ámbito territorial.

Y por último añade que cuando corresponda a la Administración General del Estado formular la declaración de impacto ambiental regulada en esta Ley, será consultado preceptivamente el órgano ambiental de la comunidad autónoma en donde se ubique territorialmente el proyecto, en los términos previstos en los artículos 8 y 9, así como, en su caso, en el artículo 17.2.

25 Ver Sebastián Félix Utrera Caro. La incidencia ambiental de las obras hidráulicas. Régimen jurídico. Dykinson. (2002); Sebastián Félix Utrera Caro. La evaluación de impacto ambiental de las obras hidráulicas. Comentario a la legislación de evaluación de impacto ambiental. 2002. At. 209-253; Sebastián Félix Utrera Caro. La evaluación ambiental de las obras hidráulicas. Derecho de aguas. Instituto Euromediterráneo del Agua. 2006. At. 909-927.

26 Ver A. Morales Plaza \& L. Cazorla González Serrano. La distribución competencial Estado-Comunidades Autónomas en materia de aguas y obras públicas hidráulicas: especial referencia a la Comunidad de Madrid. Revista Española de Derecho Administrativo. 2007, № 135. 
Quintana López ${ }^{27}$ planteó si las Comunidades Autónomas podían establecer la evaluación de impacto ambiental cuando se trate de proyectos como los trasvases que deben ser autorizados por la Administración General del Estado. Él respondía afirmativamente por la competencia autonómica de establecer normas adicionales de protección ambiental en relación con la legislación básica estatal y por la dicción de la disposición adicional tercera cuando establece que los proyectos que deban ser autorizados o aprobados por la Administración General del Estado y no hayan de sujetarse a evaluación de impacto ambiental de acuerdo con esta Ley, podrán quedar sujetos a esta evaluación cuando así lo determine la legislación de cualquier Comunidad Autónoma afectada por el proyecto. En tales casos será de aplicación lo dispuesto en el Anexo I, grupo 9, letra d) y en el Anexo II, grupo 9, letra n). ${ }^{28} \mathrm{Y}$ esta disposición añade que la evaluación a la que se refiere el apartado anterior se llevará a cabo de conformidad con el procedimiento abreviado que a tal efecto se establezca reglamentariamente por el Gobierno.

Dicho procedimiento no se ha establecido, pero, es previsible que el órgano ambiental competente sea el Ministerio de Medio Ambiente cuando el proyecto deba ser autorizado por la Administración General del Estado como palmariamente afirma el artículo 4 del Real Decreto Legislativo 1/2008 y debe ser para garantizar una unidad de criterio en toda España ante una realidad que supera a cada Comunidad Autónoma como son los trasvases.

\section{E. Contenido del estudio de impacto ambiental}

El artículo 5 se dedica a la evaluación de impacto ambiental de proyectos y señala que la evaluación de impacto ambiental de proyectos comprenderá las siguientes actuaciones:

27 Ver Quintana, supra cita 9, At. 336-337.

$28 \mathrm{El}$ Anexo I, grupo 9, letra d) establece que son proyectos comprendidos en el artículo 3.1: todos los proyectos incluidos en el Anexo II cuando sea exigida la evaluación de impacto ambiental por la normativa autonómica. El Anexo II, grupo 9, letra n) establece que son proyectos comprendidos en el artículo 3.2: n. Los proyectos que no estando recogidos en el Anexo I ni II cuando así lo requiera la normativa autonómica y a solicitud del órgano ambiental de la comunidad autónoma en la que esté ubicado el proyecto, acreditando para ello que puedan tener efectos significativos en el medio ambiente. La exigencia de evaluación de impacto ambiental por la normativa autonómica podrá servir de acreditación a efectos de este apartado. a. Solicitud por el promotor ante el órgano sustantivo de sometimiento del proyecto a evaluación de impacto ambiental, acompañada del documento inicial del proyecto.

b. Determinación del alcance del estudio de impacto ambiental por el órgano ambiental, previa consulta a las administraciones públicas afectadas y, en su caso, a las personas interesadas.

c. Elaboración del estudio de impacto ambiental por el promotor del proyecto.

d. Evacuación del trámite de información pública y de consultas a las Administraciones públicas afectadas y a personas interesadas, por el órgano sustantivo.

e. Declaración de impacto ambiental emitida por el órgano ambiental, que se hará pública y finalizará la evaluación.

Y matiza que la evaluación de impacto ambiental de proyectos en la Administración General del Estado se realizará en las siguientes fases de actuación:

- Fase 1: Determinación del alcance del estudio de impacto ambiental. Comprenderá las actuaciones descritas en el apartado 1, letras a) y b).

- $\quad$ Fase 2: Estudio de impacto ambiental, información pública y consultas. Comprenderá las actuaciones descritas en el apartado 1, letras c) y d).

- Fase 3: Declaración de impacto ambiental. Comprenderá la actuación descrita en el apartado 1, letra e).

Y concreta que la evaluación de impacto ambiental comprenderá la totalidad del proyecto y no sólo las evaluaciones de impacto ambiental parciales de cada fase o parte del proyecto.

El artículo 17.3 del RD 1131/1988, por el que se aprueba el Reglamento de ejecución de la ley estatal de evaluación de impacto ambiental, señala que las condiciones que imponga progresivamente deban adaptarse a las innovaciones aportadas por el progreso científico y técnico, en algo que hoy se formula como "mejores técnicas disponibles" en cada momento.

F. El Real Decreto Legislativo 1/2001, de 20 de julio, por el que se aprueba el texto refundido de la Ley de Aguas

Su artículo 98 se dedica a las limitaciones medioambientales a las autorizaciones y concesiones y señala que los Organismos de cuenca, en las concesiones y autorizaciones que otorguen, adoptarán las medidas necesarias para hacer compatible el aprovechamiento 
con el respeto del medio ambiente y garantizar los caudales ecológicos o demandas ambientales previstas en la planificación hidrológica.

En la tramitación de concesiones y autorizaciones que afecten el dominio público hidráulico que pudieran implicar riesgos para el medio ambiente, será preceptiva la presentación de un informe sobre los posibles efectos nocivos para el medio ambiente, del que se dará traslado al órgano ambiental competente para que se pronuncie sobre las medidas correctoras que, a su juicio, deban introducirse como consecuencia del informe presentado. Sin perjuicio de los supuestos en que resulte obligatorio, conforme a lo previsto en la normativa vigente, en los casos en que el organismo de cuenca presuma la existencia de un riesgo grave para el medio ambiente, someterá igualmente a la consideración del órgano ambiental competente la conveniencia de iniciar el procedimiento de evaluación de impacto ambiental.

El artículo 98 es desarrollado por el Real Decreto 849/1986, del 11 de abril, por el que se aprueba el Reglamento del Dominio Público Hidráulico que desarrolla los títulos preliminar, I, IV, V, VI, VII y VIII del texto refundido de la Ley de Aguas, aprobado por el Real Decreto Legislativo 1/2001, del 20 de julio, el cual establece $^{29}$ que "en la tramitación de concesiones y autorizaciones que afecten al dominio público hidráulico y pudieren implicar riesgos para el medio ambiente, será preceptiva la presentación de una evaluación de sus efectos".

Y matiza que las concesiones o autorizaciones administrativas, en relación con obras o actividades en el dominio público hidráulico, que, a juicio del organismo de cuenca, se consideren susceptibles de contaminar o degradar el medio ambiente, causando efectos sensibles en este, "requerirán la presentación por el peticionario de un estudio para evaluación de tales efectos".

Y añade que los estudios de evaluación de efectos medioambientales identificarán, preverán y valorarán las consecuencias o los efectos que las obras o actividades que el peticionario pretenda realizar puedan causar a la salubridad y al bienestar humanos y al medio ambiente, e incluirán las cuatro fases siguientes:
a. Descripción y establecimiento de las relaciones causa-efecto.
b. Predicción y cálculo en su caso de los efectos y cuan- tificación de sus indicadores.
c. Interpretación de los efectos.

29 Ver Real Decreto Legislativo 1 de 2001. Ley de Aguas. Julio 20 de 2001. d. Previsiones a medio y largo plazo y medidas preventivas de efectos indeseables.

Además, señala que "si la entidad de las obras o acciones a realizar así lo aconseja, el organismo de cuenca podrá admitir los estudios a que se refiere el presente artículo, redactados de forma simplificada y que en cualquier caso estos estudios deberán ser redactados por titulado superior competente".

A continuación asegura que si la supuesta contaminación o degradación del medio implicase afección de aguas subterráneas, el estudio incluirá la evaluación de las condiciones hidrogeológicas de la zona afectada, del eventual poder depurador del suelo y del subsuelo, y de los riesgos de contaminación y de alteración de la calidad de las aguas subterráneas por el vertido, determinando si la solución que se propone es adecuada, especialmente si se tratase de vertidos directos o indirectos.

Además, los estudios de evaluación de efectos medioambientales contenidos en las peticiones de concesiones o autorizaciones, como documentos que forman parte de los correspondientes expedientes, se verán sometidos a la tramitación normal regulada para estos, debiendo ser recabados los informes correspondientes, en relación con la afección a la salud o al medio ambiente, si por la índole de la obra o acción previstas por el peticionario, así lo estimara el organismo de cuenca.

Por último, señala que los programas, planes, anteproyectos y proyectos de obras o acciones a realizar por la propia administración, también deberán incluir los correspondientes estudios de evaluación de efectos medioambientales cuando razonablemente puedan presumirse riesgos para el medio ambiente, como consecuencia de su realización. Asimismo, deberán incorporarse dichos estudios a los expedientes de todas las obras de regulación. Estos estudios deberán adaptarse, en este caso, a lo preceptuado en el artículo 237, en lo relativo a su entidad y contenido.

El Real Decreto Legislativo 1/2001, de 20 de julio, por el que se aprueba el texto refundido de la Ley de Aguas, también recoge el artículo 129, dedicado a la Evaluación de impacto ambiental que determina que los proyectos de obras hidráulicas de interés general se someterán al procedimiento de evaluación de impacto ambiental en los casos establecidos en la legislación de evaluación de impacto ambiental. 


\section{G. La evaluación de impacto ambiental mediante acto legislativo nacional especifico ${ }^{30}$}

Los trasvases podrían ser autorizados por actos legislativos específicos y no necesitarían un procedimiento de evaluación de impacto ambiental. La reciente jurisprudencia del Tribunal de Justicia de la Unión Europea, plasmada en las sstjue del 18 de octubre del 2011 y del 16 de febrero del 2012, ha precisado cuándo puede sustituirse la evaluación de impacto ambiental por un acto legislativo nacional específico. El punto de partida se halla en el artículo 1.5 de la Directiva que exime de la obligación de evaluación a los "proyectos detallados adoptados mediante un acto legislativo nacional específico, dado que los objetivos perseguidos por la presente Directiva, incluido el objetivo de la disponibilidad de información, se consiguen a través del procedimiento legislativo". Extiende esa doctrina al artículo 2, apartado 2, del Convenio de Aarhus, que "tiene en sustancia un contenido idéntico" al del artículo 1.5 de la Directiva. Del objeto o del alcance del Convenio de Aarhus "no puede deducirse razón alguna que se oponga a que el Tribunal de Justicia extienda a la interpretación de las disposiciones de dicho Convenio la interpretación que ha enunciado para las disposiciones similares de la Directiva 85/337". Concluyó respondiendo a la segunda cuestión que los artículos 2.2 del Convenio de Aarhus y 1.5 de la Directiva 85/337 deben interpretarse en el sentido de que: a) "únicamente están excluidos del ámbito de aplicación respectivo de ambas disposiciones los proyectos detallados adoptados mediante un acto legislativo específico, de forma que los objetivos de dichas disposiciones se hayan alcanzado mediante el procedimiento legislativo". b) Corresponde al juez nacional "comprobar que se han cumplido estos dos requisitos, teniendo en cuenta tanto el contenido del acto legislativo adoptado como el conjunto del procedimiento legislativo que condujo a su adopción, y en particular los trabajos preparatorios y los debates parlamentarios". c) Si el acto legislativo se limita a "ratificar" pura y simplemente un acto administrativo preexistente, manifestando

[...] la existencia de razones imperiosas de interés general sin la previa apertura de un procedimiento legislativo de fondo que permita cumplir dichos requisitos, no

30 Ver Juan-Cruz Alli Aranguren. La evaluación ambiental de los proyectos adoptados por acto legislativo nacional específico en la jurisprudencia del Tribunal de Justicia de la Unión Europea (sTJCE de 16 de febrero de 2012). Revista Jurídica de Navarra. Julio-Diciembre 2011, No. 52. At 165-181. puede considerarse un acto legislativo específico en el sentido de la citada disposición y por lo tanto no basta para excluir un proyecto del ámbito de aplicación respectivo del citado Convenio y de dicha Directiva.

El Tribunal ha elaborado una doctrina interpretativa del precepto en los siguientes aspectos:

\section{a) Características del proyecto:}

El proyecto debe ser detallado y debe contener, "al igual que una autorización, todos los datos pertinentes para la evaluación de sus repercusiones sobre el medio ambiente", estar aprobado por un acto legislativo específico y ajustado a los objetivos de la Directiva, acreditando que sus objetivos "se han alcanzado en lo que respecta al proyecto en cuestión" (SSTJCE 16-9-1999 WWF contra Autonome Provinz Bozen, 435/97, 19-9-2000, Linster, C-287/98, 18-10-2011, Antoine Boxus y otros, C-128 a $131 / 09,134 / 09$ y 135/09, 14-2-2012, Flachglas Torgau GmgH, C-204/09, 16-2-2012). Se trata de un supuesto de "sustitución" de una autorización por otra, "dado que los objetivos perseguidos por la presente Directiva, incluido el objetivo de la disponibilidad de información, se consiguen a través del procedimiento legislativo" (art. 1.5).

\section{b) Utilización de la información administrativa:}

El legislador puede utilizar la información recopilada por el procedimiento administrativo previo (SSTJCE de 4-5-2006, Comisión contra Reino Unido, C-508/03, 16-2-2012).

c) Examen por el juez del cumplimiento de los objetivos de la Directiva:

El juez nacional tiene capacidad para examinar que el acto legislativo cumple los objetivos de la Directiva en el conjunto del procedimiento legislativo, tanto en los trabajos preparatorios como en los debates, de modo que

[...] un acto legislativo que no haga sino "ratificar" pura y simplemente un acto administrativo preexistente, limitándose a invocar la existencia de razones imperiosas de interés general sin la previa apertura de un procedimiento legislativo de fondo que permita cumplir dichos requisitos, no puede considerarse un acto legislativo específico en el sentido de la citada disposición y por lo 
tanto no basta para excluir un proyecto del ámbito de aplicación de la Directiva 85/337

[sstjCe de 8-3-2011 (Gran Sala), Lesoochranérse zozkupenie VLK, C-240/09,

18-10-2011 (Gran Sala), Antoine Boxus, C-128/89, y 16-2-2012, Marie-Noëlle

Solvar y otros, C-182/10].

d) Impugnación conforme al derecho de los Estados miembros:

Con respecto a la impugnación de los actos legislativos invocó el Convenio de Aarhus y reconoció a los Estados miembros "determinar qué órgano jurisdiccional o independiente e imparcial establecido por la ley es competente para conocer de los recursos contemplados en dichas disposiciones y con arreglo a qué cauces procesales, siempre y cuando se cumplan las referidas disposiciones" (54). Si no existiera tal recurso, "correspondería a cualquier órgano jurisdiccional que en el marco de su competencia conociese del asunto ejercer el control descrito [...] y sacar las conclusiones oportunas, dejando en su caso, sin aplicación dicho acto legislativo" (55) (sstjce de 8-3-2011 (Gran Sala), Lesoochranérse zozkupenie VLK, C-240/09, 18-10- 2011 (Gran Sala), Antoine Boxus, C-128/89, y 16-2-2012, Marie-Noëlle Solvar y otros, C-182/10).

Esta doctrina ya consolidada ha sido recogida y reiterada en la STJCE de 16 de febrero de 2012.

La segunda cuestión se formuló en cuatro puntos sobre si el artículo 2, apartado 2, del Convenio de Aarhus y el artículo 1, apartado 5, de la Directiva 85/337 deben interpretarse en el sentido de que un acto, como el Decreto del Parlamento de Valonia del 17 de julio del 2008, que "ratifica", dándoles valor legislativo, las licencias urbanísticas, medioambientales o de obras previamente concedidas por la autoridad administrativa, por "razones imperiosas de interés general", está excluido del ámbito de aplicación respectivo del Convenio y de la Directiva.

Invocó la exclusión que el artículo 1.5 de la Directiva 85/337 realizaba de su aplicación cuando los objetivos se alcanzan a través de un procedimiento legislativo, como lo habían reconocido las SsTJCE del 19 de septiembre del 2000, Linster, C-287/98, y 18 de octubre del 2011, Boxus y otros, C-128/09 y otros, que se invocaron en todos los párrafos que analizaron la cuestión. Por tanto, dedujo que
[...] dicha disposición sujeta a dos requisitos la exclusión de un proyecto del ámbito de aplicación de la Directiva $85 / 337$. El primero es que se trate de un proyecto detallado adoptado mediante un acto legislativo específico. El segundo es que se alcancen los objetivos de la Directiva, incluido el objetivo de la disponibilidad de informaciones, a través del procedimiento legislativo

(ssTJCE de 16 de septiembre de 1999, wwF y otros, C-435/97, y 18 de octubre de 2011, Boxus y otros, C-128/09 y otros).

Analizó los requisitos exigidos:

a) El primero que se trate de un proyecto, conforme a los conceptos del artículo 1.2., "detallado adoptado mediante un acto legislativo nacional específico", con las "mismas características que esa autorización", que confiera a su titular "el derecho a realizarlo", invocando las sentencias anteriores. De modo que el acto legislativo debe contener los elementos suficientes del proyecto, de manera "suficientemente precisa y definitiva, de suerte que comporte en el momento de la autorización, cuando sea tomada en consideración por el legislador, todos los elementos del proyecto necesarios para la evaluación de sus repercusiones sobre el medio ambiente (STJCE de 16 de septiembre de 1999, WWF y otros, 435/97). Los datos y detalles del proyecto necesarios para evaluar sus repercusiones en el medio ambiente y autorización deben incorporarse al acto legislativo, acreditando que se alcanzaban los objetivos de la Directiva, conforme a las sentencias citadas. Como consecuencia, deduce que

[...] no cabe considerar que un acto legislativo adopte un proyecto detallado, a efectos del artículo 1, apartado 5 , de la Directiva 85/337, cuando no contenga los datos necesarios para la evaluación de las repercusiones de dicho proyecto sobre el medio ambiente, o requiera la adopción de otros actos para conferir al titular del proyecto el derecho a realizarlo.

b) El segundo requisito era cumplir el objetivo esencial de la Directiva 85/337 que es garantizar que, antes de concederse una autorización, los proyectos que puedan tener repercusiones importantes sobre el medio ambiente (art. 1.1), en particular debido a su naturaleza, sus dimensiones o su localización, se sometan a una evaluación en lo que se refiere a sus repercusiones sobre el medio ambiente (art. 2.1). De modo que no pueden excluirse de la evaluación (STJCE 20 de no- 
viembre de 2008, Comisión/Irlanda, C-66/06, 16 de julio de 2009, Comisión/Irlanda, C-427/07). Para poder hacerlo era preciso conocer la información, invocando el considerando sexto de la Directiva, el artículo 5.3 y su anexo IV respecto a la información proporcionada por el titular del proyecto o por las autoridades y los interesados, incluidas las medidas previstas para compensar los efectos adversos significativos sobre el medio ambiente. Observó que la Directiva 85/337 no se oponía a que un mismo proyecto fuera aprobado mediante dos actos de Derecho nacional, considerados conjuntamente como una autorización en el sentido de su artículo 1 (sTJCE de 4 de mayo de 2006, Comisión contra Reino Unido, C-508/03): "Por consiguiente, el legislador puede, al adoptar el acto final de autorización de un proyecto, servirse de la información recopilada en el marco de un procedimiento administrativo previo", invocando la Sentencia Boxus.

La existencia de un procedimiento administrativo no implica que se produzca la exigencia de que sea detallado el proyecto que se adopte por acto legislativo específico, conforme al artículo 1.5 de la Directiva $85 / 337$. Sus requisitos deben cumplirse por dicho acto, como expuso en la Sentencia Boxus:

[...] un acto legislativo que no hiciera sino ratificar pura y simplemente un acto administrativo preexistente, limitándose a invocar la existencia de razones imperiosas de interés general sin la previa apertura de un procedimiento legislativo de fondo que permita cumplir dichos requisitos, no puede considerarse un acto legislativo específico en el sentido de la citada disposición y por lo tanto no basta para excluir un proyecto del ámbito de aplicación de la Directiva 85/337.

Por tanto, se exige que "los miembros del órgano legislativo hayan tenido a su disposición la información mencionada en el apartado 37", ya que sin ella "no puede estar comprendido en el ámbito de aplicación del artículo 1, apartado 5, de la Directiva 85/337".

Se reconoce al juez nacional capacidad para "determinar si se han cumplido estos requisitos", teniendo en cuenta "tanto el contenido del acto legislativo adoptado como el conjunto del procedimiento legislativo que condujo a su adopción, y en particular los trabajos preparatorios y los debates parlamentarios", como se recogió en la Sentencia Boxus.

Extiende esa doctrina al artículo 2, apartado 2, del Convenio de Aarhus, que "tiene en sustancia un contenido idéntico" al del artículo 1.5 de la Directiva. Del objeto o del alcance del Convenio de Aarhus "no puede deducirse razón alguna que se oponga a que el Tribunal de Justicia extienda a la interpretación de las disposiciones de dicho Convenio la interpretación que ha enunciado para las disposiciones similares de la Directiva 85/337". Concluyó respondiendo a la segunda cuestión que los artículos 2.2 del Convenio de Aarhus y 1.5 de la Directiva 85/337 deben interpretarse en el sentido de que a) "únicamente están excluidos del ámbito de aplicación respectivo de ambas disposiciones los proyectos detallados adoptados mediante un acto legislativo específico, de forma que los objetivos de dichas disposiciones se hayan alcanzado mediante el procedimiento legislativo". b) Corresponde al juez nacional "comprobar que se han cumplido estos dos requisitos, teniendo en cuenta tanto el contenido del acto legislativo adoptado como el conjunto del procedimiento legislativo que condujo a su adopción, y en particular los trabajos preparatorios y los debates parlamentarios". c) Si el acto legislativo se limita a "ratificar" pura y simplemente un acto administrativo preexistente, manifestando

[...] la existencia de razones imperiosas de interés general sin la previa apertura de un procedimiento legislativo de fondo que permita cumplir dichos requisitos, no puede considerarse un acto legislativo específico en el sentido de la citada disposición y por lo tanto no basta para excluir un proyecto del ámbito de aplicación respectivo del citado Convenio y de dicha Directiva.

También debe considerarse la Sentencia del Tribunal de Justicia de la Unión Europea (Gran Sala), del 11 de septiembre del 2012, asunto C-43/10, por la que se resuelve la cuestión prejudicial planteada con arreglo al artículo 267 TFUE, en relación con la interpretación de determinados preceptos de las Directivas "marco" de aguas, de evaluación de impacto ambiental de proyectos, de planes y programas y de hábitats a un litigio sobre trasvase de recursos hídricos en Grecia. ${ }^{31}$

\footnotetext{
31 Ver Ángel Ruiz de Apodaca Espinosa. Tribunal de Justicia de la Unión Europea. Revista Actualidad Jurídica Ambiental. 11 de octubre del 2012. At 28. El autor opina que en el presente caso, el Tribunal de Justicia a través de su Gran Sala responde a un elevado número de cuestiones prejudiciales planteadas por el tribunal griego en relación con un trasvase de recursos hídricos aprobado finalmente ex lege tras haber sido anulado por los propios tribunales griegos en más de una ocasión. Las respuestas del Tribunal de Justicia están lejanas de una interpretación ambientalista de la propia legislación ambiental que se invoca en el proceso, desde la propia aplicación de la Directiva marco de aguas y sus excepciones, pasando por la elusión de la evaluación de impacto ambiental, de la necesaria participación y de la admisión de un trasvase que afecta a un LIC so pretexto de la causa de razón imperiosa de interés público.
} 
La cuestión prejudicial se plantea en el marco de los recursos de anulación interpuestos por la Administración Autónoma Provincial de Etolia-Acarnania, y por otras personas jurídicas contra el ministro de $\mathrm{Me}$ dio Ambiente, Ordenación del Territorio y Obras Públicas, y contra otros ministros, cuyo objeto son actos relativos al proyecto de desviación parcial del curso superior de las aguas del río Acheloos (Grecia occidental) hacía el río Pineo, en Tesalia. Este proyecto de gran dimensión, pretende responder no sólo a las necesidades de regadío de la región de Tesalia y a la producción de electricidad, sino también al abastecimiento de agua para núcleos urbanos de esa región.

El 2 de agosto del 2006 se adoptó la Ley 3481/2006, cuyos artículos 9 y 13 aprobaban el proyecto discutido en el litigio principal. El artículo 9 de esa Ley disponía que, hasta la aprobación del programa nacional de gestión y de protección de los recursos hídricos nacionales y la adopción de los planes de gestión de las regiones, se podrían aprobar los planes hidrológicos de cuencas hidrográficas específicas, así como los trasvases de aguas a otras cuencas, si bien habrían de aprobarse por ley los proyectos relacionados con esos planes cuando se tratara de un proyecto de gran amplitud o de importancia nacional. El artículo 13 de dicha Ley calificó las obras relacionadas con el citado proyecto como obras de gran amplitud e interés nacional, y aprobó el plan hidrológico de las cuencas hidrográficas de los ríos Acheloos y Peneo, así como las especificaciones medioambientales aplicables a la construcción y el funcionamiento de las obras inherentes a ese proyecto.

El artículo 13, apartado 4, de la Ley 3481/2006 preveía que, de conformidad con el plan hidrológico y los parámetros medioambientales aprobados en el apartado 3 del mismo artículo, se podía poner en funcionamiento o finalizar la construcción de las obras públicas y de las obras relacionadas con la desviación del curso superior de las aguas del río Acheloos hacia Tesalia, o con la producción de energía eléctrica, para las que se había adjudicado un contrato público y que se habían ejecutado o estaban en fase de ejecución. Con fundamento en esa disposición, se ordenó a la sociedad adjudicataria proseguir las obras que había suspendido a raíz de la sentencia que anuló la adjudicación del contrato.

Los demandantes en el litigio principal solicitan la anulación de la totalidad del proyecto discutido en ese litigio. Los recursos impugnan tanto el artículo 13 de la Ley 3481/2006 como los actos administrativos conexos. El "Symvoulio tis Epikrateias" órgano que plantea la cuestión prejudicial expone que tanto los actos de aprobación de los parámetros medioambientales como los actos en virtud de los que debían ejecutarse las obras inherentes a ese proyecto ya habían sido anulados por sentencias de ese tribunal antes de la entrada en vigor de la Ley 3481/2006. Según el tribunal remitente, se pretende, así pues, adoptar de nuevo esos actos a través del plan hidrológico antes mencionado, que fue aprobado con fundamento en el artículo 9 de esa Ley.

La cuestión más importante que suscita el litigio principal es la de la compatibilidad con el Derecho de la Unión de los artículos 9 y 13 de dicha Ley.

El tribunal remitente plantea varias cuestiones prejudiciales, el tribunal remitente pregunta ante todo si la Directiva 2000/60 debe interpretarse en el sentido de que se opone a una disposición nacional que autorizaba, antes del 22 de diciembre del 2009, un trasvase de agua de una cuenca hidrográfica a otra o de una demarcación hidrográfica a otra, cuando las autoridades nacionales competentes aún no habían adoptado los planes hidrológicos de las cuencas hidrográficas de que se trata. En caso de respuesta negativa, desea saber además si ese trasvase puede realizarse sólo para fines de abastecimiento de población, o también para regadío y para producción de energía. Finalmente, ese tribunal pregunta si la compatibilidad de ese trasvase con la citada Directiva está condicionada a la imposibilidad de que la cuenca hidrográfica o la demarcación hidrográfica receptora satisfaga con sus propios recursos hídricos sus necesidades de abastecimiento de población, de producción de energía o de regadío.

Igualmente se plantean varias cuestiones prejudiciales en relación con la interpretación al supuesto concreto de las Directivas de EIA, EAE y Hábitats.

Destacamos los siguientes extractos:

53. [...] la Directiva 2000/60 no prohíbe a priori el trasvase de agua de una cuenca hidrográfica a otra o de una demarcación hidrográfica a otra antes de la publicación de los planes hidrológicos de las cuencas hidrográficas afectadas, la cual debía realizarse no obstante, a más tardar, el 22 de diciembre de 2009, conforme al artículo 13, apartado 6, de esa Directiva.

55. [...] cuando se adoptó el proyecto discutido en el litigio principal la República Helénica no estaba obligada a haber elaborado los planes hidrológicos de las cuencas hidrográficas afectadas por ese proyecto. En efecto, si bien el plazo para la transposición de la Directiva 2000/60, fijado por su artículo 24, apartado 1 , párrafo primero, había finalizado, en cambio el plazo previsto por el artículo 13, apartado 6, de la misma Di- 
rectiva para la publicación de los planes hidrológicos de cuenca hidrográfica aún no había terminado.

56. Por tanto, el artículo 4 de la Directiva 2000/60 no era aplicable al proyecto discutido en el litigio principal, adoptado por el legislador griego el 2 de agosto de 2006 sin que se hubieran elaborado previamente los planes hidrológicos de las demarcaciones hidrográficas de las que forman parte las cuencas hidrográficas afectadas por ese proyecto.

57. Sin embargo, se debe recordar que, de conformidad con reiterada jurisprudencia, durante el plazo de adaptación del derecho interno a una directiva, los Estados miembros destinatarios de esta deben abstenerse de adoptar disposiciones que puedan comprometer gravemente el resultado prescrito por esta. Puesto que tal obligación de abstención se impone a todas las autoridades nacionales, debe entenderse que se refiere a la adopción de cualquier medida, general o específica, que pueda producir ese efecto negativo [...]

60. De tal forma, aun antes del 22 de diciembre del 2009, fecha de expiración del plazo prescrito por el artículo 13, apartado 6, de la Directiva 2000/60, para la publicación por los Estados miembros de los planes hidrológicos de las cuencas hidrográficas, los Estados miembros debían abstenerse de adoptar disposiciones que pudieran comprometer gravemente la consecución del resultado exigido por el artículo 4 de esa Directiva.

62. Una medida nacional, aun si fue adoptada antes del 22 de diciembre de 2009, no puede, sin perjuicio de ciertas reservas, comprometer la realización de dicho objetivo.

67. En consecuencia, un proyecto como el discutido en el litigio principal, al que no es aplicable el artículo 4 de la Directiva 2000/60, y que podría haber causado efectos negativos para el agua como los enunciados en el apartado 7 de ese artículo, podía ser autorizado, cuando menos:

- Si se habían adoptado todas las medidas factibles para paliar los efectos adversos en el estado de la masa de agua.

- Si los motivos por los que debía realizarse dicho proyecto se habían consignado y explicado específicamente.

- Si ese proyecto respondía a un interés público que podía consistir, en particular, en el abastecimiento de agua para la población, en la producción de energía o en el regadío, o si los beneficios para el medio ambiente y la sociedad ligados al logro de los objetivos previstos en el apartado 1 de dicho artículo eran inferiores a los beneficios para la salud humana, el mantenimiento de la seguridad humana o el desarrollo sostenible derivados de dicho proyecto.

- Por último, si los beneficios obtenidos por ese proyecto no podían conseguirse, por motivos de viabilidad técnica o de costes desproporcionados, por otros medios que constituyeran una opción medioambiental significativamente mejor.

69. Por las anteriores consideraciones, procede responder a las cuestiones segunda a cuarta que la Directiva 2000/60 debe interpretarse en el sentido de que: - No se opone, en principio, a una disposición nacional que autorizó, antes del 22 de diciembre del 2009 , un trasvase de agua de una cuenca hidrográfica a otra o de una demarcación hidrográfica a otra, cuando las autoridades nacionales competentes aún no habían adoptado los planes hidrológicos de las cuencas hidrográficas afectadas.

- Ese trasvase no debe poder comprometer gravemente la consecución de los objetivos prescritos por dicha Directiva.

- No obstante, en el caso de que ese trasvase pudiera causar efectos negativos para el agua como los enunciados en el artículo 4, apartado 7, de la misma Directiva, puede ser autorizado, cuando menos, si concurren las condiciones previstas en los puntos a) a d) de esa misma disposición.

- La imposibilidad de que la cuenca hidrográfica o la demarcación hidrográfica receptora satisfaga con sus propios recursos hídricos sus necesidades de abastecimiento de población, de producción de energía o de regadío no es una condición indispensable para que ese trasvase de aguas sea compatible con la referida Directiva si se cumplen las condiciones antes mencionadas.

Sobre la ausencia de participación en la aprobación del citado plan hidrológico:

74. [...] los planes hidrológicos de las cuencas hidrográficas, como los que son objeto del litigio principal, adoptados el 2 de agosto del 2006, no pueden considerarse como planes hidrológicos comprendidos en los artículos 13 a 15 de la Directiva 2000/60. Por tanto, la obligación derivada del artículo 14, apartado 1, de esta no es aplicable a esos planes. 
75. [...] el hecho de que un Parlamento nacional apruebe planes hidrológicos de cuencas hidrográficas, como los que son objeto del litigio principal, sin que se haya tramitado ningún procedimiento de información, consulta y participación del público no entra en el campo de aplicación del artículo 14 de la Directiva 2000/60, y en especial de su apartado 1.

Sobre la falta de sometimiento a evaluación de impacto ambiental:

77. Hay que recordar que el artículo 1 , apartado 5, de la Directiva 85/337 dispone que esta «no se aplicará a los proyectos detallados adoptados mediante un acto legislativo nacional específico, dado que los objetivos perseguidos por la presente Directiva, incluido el objetivo de la disponibilidad de informaciones, se consiguen a través del procedimiento legislativo».

91. Por consiguiente, procede responder a la sexta cuestión que la Directiva 85/337, y en particular su artículo 1, apartado 5, debe interpretarse en el sentido de que no se opone a una ley como la Ley 3481/2006, adoptada por el Parlamento griego el 2 de agosto del 2006, que aprueba un proyecto de desviación parcial de las aguas de un río, como el discutido en el litigio principal, con fundamento en un EIA de ese proyecto que había servido como base para una resolución administrativa adoptada al término de un procedimiento conforme con las obligaciones de información y de participación del público previstas por esa Directiva, a pesar de que esa resolución fue anulada en vía jurisdiccional, siempre que dicha Ley constituya un acto legislativo específico, de modo tal que los objetivos de esa Directiva puedan alcanzarse a través del procedimiento legislativo. Corresponde al juez nacional verificar el cumplimiento de esas dos condiciones.

Sobre la ausencia de evaluación ambiental estratégica del citado plan:

96. En consecuencia, procede responder a la séptima cuestión que un proyecto de desviación parcial de las aguas de un río, como el discutido en el litigio principal, no debe considerarse como un plan o un programa comprendido en el campo de aplicación de la Directiva 2001/42.

Sobre la afectación a los LIC declarados por el Estado y la interpretación del artículo 6 de la Directiva de Hábitats:
105. [...] las zonas que figuraban en la lista nacional de los LIC, comunicada a la Comisión en aplicación del artículo 4, apartado 1, párrafo segundo, de la Directiva 92/43 e incluidas a continuación en la lista de los LIC aprobada por la Decisión 2006/613 se beneficiaban, tras la notificación de esta última al Estado miembro interesado, de la protección de esa Directiva antes de la publicación de la Decisión mencionada. En particular, tras esa notificación, el Estado miembro interesado también debía tomar las medidas de protección previstas en el artículo 6, apartados 2 a 4, de esa Directiva.

117. [...] la Directiva 92/43, y en especial su artículo 6, apartados 3 y 4 , debe interpretarse en el sentido de que se opone a que sea autorizado un proyecto de desviación de aguas, no directamente relacionado con la preservación de una ZPE o necesario para la misma, pero que puede afectarla de forma apreciable, a falta de información o datos fiables y actualizados relativos a la fauna aviaria de esa zona.

128. Por cuanto se ha expuesto, procede responder a la duodécima cuestión que la Directiva 92/43, y en particular su artículo 6, apartado 4, debe interpretarse en el sentido de que los motivos ligados al regadío, por un lado, y por otro al abastecimiento de agua potable para la población, invocados en apoyo de un proyecto de desviación de aguas, pueden constituir razones imperiosas de interés público de primer orden que justifiquen la realización de un proyecto que perjudique la integridad de los lugares afectados. Cuando un proyecto de esa clase perjudique la integridad de un LIC que albergue un tipo de hábitat natural o una especie prioritarios, su realización puede justificarse en principio por razones ligadas al abastecimiento de agua para la población y en la primordial importancia que el regadío tiene para el medio ambiente. En cambio, el regadío no puede corresponder en principio a consideraciones ligadas a la salud humana y a la seguridad pública aptas para justificar la realización de un proyecto como el discutido en el litigio principal.

133. [...] en virtud de la Directiva 92/43, y en especial de su artículo 6 , apartado 4, párrafo primero, primera frase, deben tomarse en consideración el alcance de la desviación de aguas y la dimensión de las obras que esta exige, para determinar las medidas compensatorias adecuadas.

139. [...] la Directiva 92/43, y en particular su artículo 6, apartado 4, párrafo primero, interpretada a la luz del objetivo de desarrollo sostenible, reconocido en el artículo 6 TCE, permite, en lugares que forman parte de 
la red Natura 2000, la transformación de un ecosistema fluvial natural en un ecosistema fluvial y lacustre fuertemente antrópico siempre que se cumplan las condiciones previstas por esa disposición de dicha Directiva.

\section{Conclusiones}

- Tanto en Europa como en España, los trasvases de aguas entre cuencas fluviales necesitan someterse a evaluación ambiental estratégica y a evaluación de impacto ambiental por expresa disposición de la Ley del Plan Hidrológico Nacional y de las legislaciones de evaluación ambiental.

- La evaluación de impacto ambiental puede sustituirse por la aprobación del proyecto mediante un acto legislativo nacional específico, lo que tiene la ventaja de poder ser recurrido ante el Tribunal Constitucional que normalmente resolverá cuando el proyecto esté ejecutado y dando la razón al Parlamento.

- El trasvase del Ebro puede aprobarse mediante un acto legislativo nacional específico que cumpla los objetivos de la legislación de evaluación ambiental.

\section{REFERENCIAS}

A. Morales Plaza \& L. Cazorla González Serrano. La distribución competencial Estado-Comunidades Autónomas en materia de aguas y obras públicas hidráulicas: especial referencia a la Comunidad de Madrid. Revista Española de Derecho Administrativo. 2007, No. 135.

Anna Pallares Serrano. La planificación hidrológica de cuenca como instrumento de ordenación ambiental sobre el territorio. Tirant Lo Blanch. (2007).

Ángel Ruiz de Apodaca Espinosa. Tribunal de Justicia de la Unión Europea. Revista Actualidad Jurídica Ambiental. 11 de octubre del 2012. At 28.

Antonio Ezquerra Huerva. El régimen jurídico de las obras hidráulicas. Instituto Euromediterráneo del Agua. (2007).

Antonio Fanlo Loras. La Directiva Marco de Aguas: base jurídica medioambiental y principales contenidos. Revista Aranzadi de Derecho Ambiental. 2002, vol. 2. At. 57.

Antonio Fanlo Loras. La unidad de gestión de las cuencas hidrográficas. Editorial Instituto Euromediterráneo del Agua. (2007).

Antonio Fanlo Loras. La ordenación jurídica del Trasvase Tajo-Segura. Editorial Instituto Euromediterráneo del Agua. (2008).
Antonio Fanlo Loras. El trasvase Tajo-Segura y su instrumentación jurídica. Editorial Civitas. (2008).

Isabel Gallego Córceles. Régimen jurídico de los trasvases. Thomson Reuters - Civitas - Cortes. (2009).

Joaquín Melgarejo Moreno. El trasvase Tajo-Segura: repercusiones económicas, sociales y ambientales en la cuenca del Segura. Editorial Caja de Ahorros del Mediterráneo. (2009).

Joaquín Melgarejo Moreno, Andrés Molina Giménez \& Alberto del Villar García. El valor socioeconómico del Trasvase Tajo-Segura: análisis jurídico y económico ante la hipótesis de su reducción o cancelación. Editorial Fundación Coepa para la formación. (2009).

Jorge Agudo González. Ejecución y gestión de obras hidráulicas. Nuevos retos, nuevos conflictos, Comares. (2008).

Jorge Agudo González. El Derecho de aguas en clave europea. La Ley. (2010).

José Antonio Razquín Lizárraga. La evaluación de impacto ambiental. Aranzadi. (2000).

Juan Cruz Alli Aranguren. El Plan Hidrológico Nacional y la evaluación ambiental estratégica. El Derecho de aguas en Iberoamérica y España: cambio y modernización en el inicio del tercer milenio, 2002 vol. I. At. 355.

Juan Cruz Alli Aranguren. La Directiva 2011/92/UE, codificación del régimen de la evaluación de impacto ambiental de proyectos. Una ocasión perdida para mejorar el sistema. Revista de Derecho Urbanístico y Medio Ambiente. 2012, No. 275. At 127-176.

Juan Cruz Alli Aranguren. La evaluación ambiental de los proyectos adoptados por acto legislativo nacional específico en la jurisprudencia del Tribunal de Justicia de la Unión Europea (sTJCE de 16 de febrero de 2012). Revista Jurídica de Navarra. Julio-Diciembre 2011, No. 52. At 165-181.

Juan Rosa Moreno. Régimen jurídico de la evaluación de impacto ambiental. Trivium. (1993).

Juan Rosa Moreno. La evaluación ambiental estratégica en la planificación de infraestructuras. III Congreso Nacional de Derecho Ambiental. (2000).

Lorenzo Mellado Ruiz. Gestión sostenible del agua y evaluación de impacto ambiental de obras hidráulicas. Comares. (2004).

Nuria Garrido Cuenca. La evaluación ambiental estratégica de políticas, planes y programas. Revista Aranzadi de Derecho Ambiental. 2004 No. 5.

Nuria Garrido Cuenca. Intervención pública y sostenibilidad medioambiental: análisis desde el punto de vista de la organización administrativa y la integración de los principios de coordinación, cooperación y participación. Situación actual, balance y perspectivas. Revista Aranzadi de Derecho Ambiental. 2008, No. 13. At. 272. 
Ramón Martín Mateo. Sobre trasvases, concesiones y convenios. El suministro de agua a la comarca del Vinalopó. Revista Española de Derecho Administrativo. 1997 No. 96.

Real Decreto Legislativo 1 de 2001. Ley de Aguas. Julio 20 del 2001.

Ricardo Almenar \& Emerit Bono. Trasvase del Ebro y Comunidad Valenciana. Tirant Lo Blanch. (2005).

Sebastián Félix Utrera Caro. La incidencia ambiental de las obras hidráulicas. Régimen jurídico. Dykinson. (2002).

Sebastián Félix Utrera Caro. La evaluación de impacto ambiental de las obras hidráulicas. Comentario a la legislación de evaluación de impacto ambiental. 2002. At. 209.

Sebastián Félix Utrera Caro. La evaluación ambiental de las obras hidráulicas. Derecho de aguas. Instituto Euromediterráneo del Agua. 2006. At. 909-927.
Sebastián Martín Retortillo Baquer. Derecho de aguas. Editorial Civitas. (1997).

Teresa Parejo Navajas. Comentario sobre la Directiva 2011/92/ UE del Parlamento Europeo y del Consejo, de 13 de diciembre de 2011, relativa a la evaluación de las repercusiones de determinados proyectos públicos y privados sobre el medio ambiente. Revista General de Derecho Europeo. 2012, No. 27.

Tomás Quintana López. La evaluación ambiental de los trasvases y sus actuaciones. La ordenación jurídica del Trasvase Tajo-Segura. Pág. 337. Fundación Instituto Euromediterráneo del Agua. (2008).

Tribunal de Justicia. Sala Cuarta. (22 de marzo de 2012).

Tribunal Supremo. Sección 5a Sala de lo Contencioso-Administrativo. (Ponente: Jesús Ernesto Peces Morate / 2012). 